\title{
Nicotine induced haemodynamic changes during cigarette smoking and nicotine gum chewing: a placebo controlled study in young healthy volunteers
}

\author{
HENRI BOUNAMEAUX, MARTHE GRIESSEN, PIA BENEDET, BERNARD KRAHENBUHL, \\ ANDRÉ DEOM \\ From the Unit of Angiology, Medical Polyclinic, Department of Medicine and Toxicology Unit, Central Clinical \\ Chemistry Laboratory, University Hospital of Geneva, Geneva, Switzerland
}

ABSTRACT Because cigarette smoking is a definite risk for the development of cardiovascular disease and nicotine induced vasoconstriction may be a possible pathogenetic factor the haemodynamic effects of smoking cigarettes with high or low nicotine content were compared with those induced by chewing nicotine gum in a placebo controlled, crossover study in six healthy volunteers. The three stimuli induced similar increases in heart rate (about 20\%) and systolic blood pressure (about $7 \%$ ) and a decrease in digital blood flow. Although the mean haemodynamic changes parallelled the mean plasma nicotine concentration increases, no correlation was found between them when the individual values were considered. It is concluded that the nicotine induced haemodynamic changes probably occur as a result of the (local) release of vasoactive mediators such as adrenaline or noradrenaline after a threshold plasma nicotine concentration has been reached. Such a threshold may explain the large interindividual variability in susceptibility to smoking induced cardiovascular diseases.

Epidemiological studies have established a clear relation between cigarette smoking and cardiovascular diseases such as myocardial infarction ${ }^{1}$ and peripheral arterial occlusive disease. ${ }^{2}$ However, the pathogenesis of these smoking induced cardiovascular events is not completely understood. Several mechanisms have been proposed, including vasospasm due to $(a)$ nicotine induced release of adrenergic catecholamines, ${ }^{3}$ thus producing vasoconstriction and increased heart rate; $(b)$ increased release of the vasoconstrictor thromboxane $\mathrm{A}_{2}$ and a reduction of the endothelial production of prostacyclin, a potent vasodilator and platelet antiaggregating substance ${ }^{4-6}$; and $(c)$ increase of the carboxyhaemoglobin content of

Address for correspondence and reprints: Dr $\mathrm{H}$ Bounameaux. Unit of Angiology, Medical Policlinic, University Hospital of Geneva, CH-1211 Geneva 4, Switzerland.

Key words: nicotine; tachycardia; blood pressure: peripheral vascular resistance; cigarette; nicotine gum

Submitted 25 May 1987

Accepted 24 September 1987 blood with a possible decrease of the oxygen supply to the endothelial cell. ${ }^{7}$

In the present study, we compared the haemodynamic response of young healthy smokers to three different nicotine stimuli: a cigarette with high or low nicotine content and a nicotine chewing gum. These three stimuli were compared with a placebo in a crossover study, ${ }^{8}$ and the induced haemodynamic changes were correlated with increases in the plasma nicotine concentration.

\section{Subjects and methods}

STUDY PROTOCOL

Six healthy male smokers (mean(SD) age 30(2.8) years; mean(SD) cigarette consumption 8.2 (1.1) pack year, where 1 pack year corresponds to smoking 1 pack of 20 cigarettes per day during one year) were enrolled in a crossover, placebo controlled study. The trial was carried out according to the Declaration of Helsinki and was approved by the human ethical committee of our institution. The study consisted of 
four periods, which were separated from each other by at least $24 \mathrm{~h}$. Smoking or chewing was prohibited during the 12 hours preceding each period. The sequence of the following four periods was randomised: smoking (in $5 \mathrm{~min}$ ) a filter cigarette containing 1.2 or $0.1 \mathrm{mg}$ of nicotine or chewing (during $45 \mathrm{~min}$ ) a gum containing $4 \mathrm{mg}$ of nicotine or an ordinary arabic gum.

\section{EXPERIMENTAL PROCEDURE}

Before the start of each period volunteers lay for at least $20 \mathrm{~min}$ in a room at a constant temperature $\left(22^{\circ} \mathrm{C}\right)$. A butterfly needle was inserted in an antecubital vein of the right arm through which $5 \%$ glucose was slowly infused (about $1 \mathrm{ml} \cdot \mathrm{min}^{-1}$ ). A sphygmomanometer cuff was placed around the right arm and humeral systolic (SBP) and diastolic (DBP) blood pressure and heart rate (HR) were recorded at 5 min intervals using an automatic device (Accutor, Datascope Corp, New Jersey). Digital blood flow (BF) was measured every $5 \mathrm{~min}$ in the left third finger, the arm being raised to heart level, using venous occlusion plethysmography. Briefly, a cuff was placed around the proximal phalanx of the finger and a mercury strain gauge around the distal phalanx. The cuff was then rapidly inflated to $50 \mathrm{mmHg}$. The digital blood flow was derived from the slope of the initial increase of the finger volume after cuff inflation and expressed in $\mathrm{ml} \cdot \mathrm{min}^{-1}$ per $100 \mathrm{ml}$ tissue. The peripheral vascular resistance (PVR) was then calculated using the following formula9:

$$
P V R=(S B P+2 D B P) / 3 B F
$$

and expressed in arbitrary units (AU). A thermistor probe was fixed on the second finger of the left hand for measuring skin temperature and an electrode attached to the dorsum of the left foot for recording transcutaneous partial oxygen tension ${ }^{10}$ at $5 \mathrm{~min}$ intervals. All measurements were carried out for 45 min from the start of smoking or chewing.

Blood samples were taken by the double syringe technique just before the start of each period and after 5,30 , and $45 \mathrm{~min}$ in tubes containing lithium heparinate for measuring whole blood carboxyhaemoglobin and plasma nicotine concentration. The carboxyhaemoglobin content of venous blood was measured within $30 \mathrm{~min}$ of sampling using a CO-oxymeter (Corning 2500, CIBA-Corning, Switzerland). Plasma was obtained by centrifugation of the heparinised blood at $3000 \mathrm{~g}$ for $10 \mathrm{~min}$. Aliquots were stored at $-20^{\circ} \mathrm{C}$ until the assay for nicotine was performed by gas liquid chromatography. "1

\section{ANALYSIS OF THE DATA}

Using a method previously described, ${ }^{12}$ the values of blood flow and peripheral vascular resistance were log transformed to obtain a normal distribution. For each variable, the area under the curve (AUC) was calculated for the $45 \mathrm{~min}$ period of observation. These values were compared by one way analysis of variance. Linear regression analysis was used to study correlations between the changes in the various haemodynamic variables and the increases in the plasma nicotine concentrations using the AUC values. Unless stated otherwise, all values are given as mean(SEM).

\section{Results}

Both cigarette smoking and nicotine gum chewing were associated with increases of systolic blood pressure (fig la) $(\mathrm{p}<0.05)$ and heart rate (fig lb) $(\mathrm{p}<0.001)$ compared with placebo. The maximal increase of systolic blood pressure was $9 \%, 4 \%$, and $7 \%$ of the baseline value for the cigarette with high or low nicotine content and for the nicotine gum respectively. The corresponding figures for the maximal increase of heart rate were $25 \%, 18 \%$, and $25 \%$. A significant decrease $(\mathrm{p}<0.05)$ in digital blood flow (fig lc) during the $45 \mathrm{~min}$ observation period was recorded only after smoking the cigarette with high nicotine content. A similar trend $(0.05<p<0.1)$ was also observed with the nicotine gum, whereas no significant change in blood flow was seen after smoking the cigarette with low nicotine content. Although considerable increases in calculated peripheral vascular resistance were obtained (fig 1d), they did not reach the level of statistical significance because of the large interindividual variations in the response to the different stimuli. Whereas the maximal haemodynamic changes were seen very early (at 5 min) after cigarette smoking they occurred between 10 and $20 \mathrm{~min}$ after nicotine gum chewing. With the latter, the maximal decrease in digital blood flow was not reached even after $45 \mathrm{~min}$.

No consistent changes in skin temperature or transcutaneous partial oxygen tension were observed with the different stimuli (data not shown).

The maximal increase in plasma nicotine concentration (fig 2a) was obtained after $5 \mathrm{~min}$ with the two cigarettes $\left(87(22) \mathrm{nmol} \cdot \mathrm{litre}^{-1}\right.$ and $62(24)$ nmol-litre ${ }^{-1}$ after the cigarette with high or low nicotine content respectively (NS)). The corresponding figure was $55(8) \mathrm{nmol} \cdot \mathrm{litre}^{-1}$ for the nicotine gum after $45 \mathrm{~min}$.

The increases in nicotine concentrations over the 45 min observation period did not differ statistically from each other for the three nicotine stimuli. The carboxyhaemoglobin content of whole blood increased significantly after both cigarettes compared with the nicotine gum and placebo (fig $2 b$ ). The increase was significantly more pronounced 

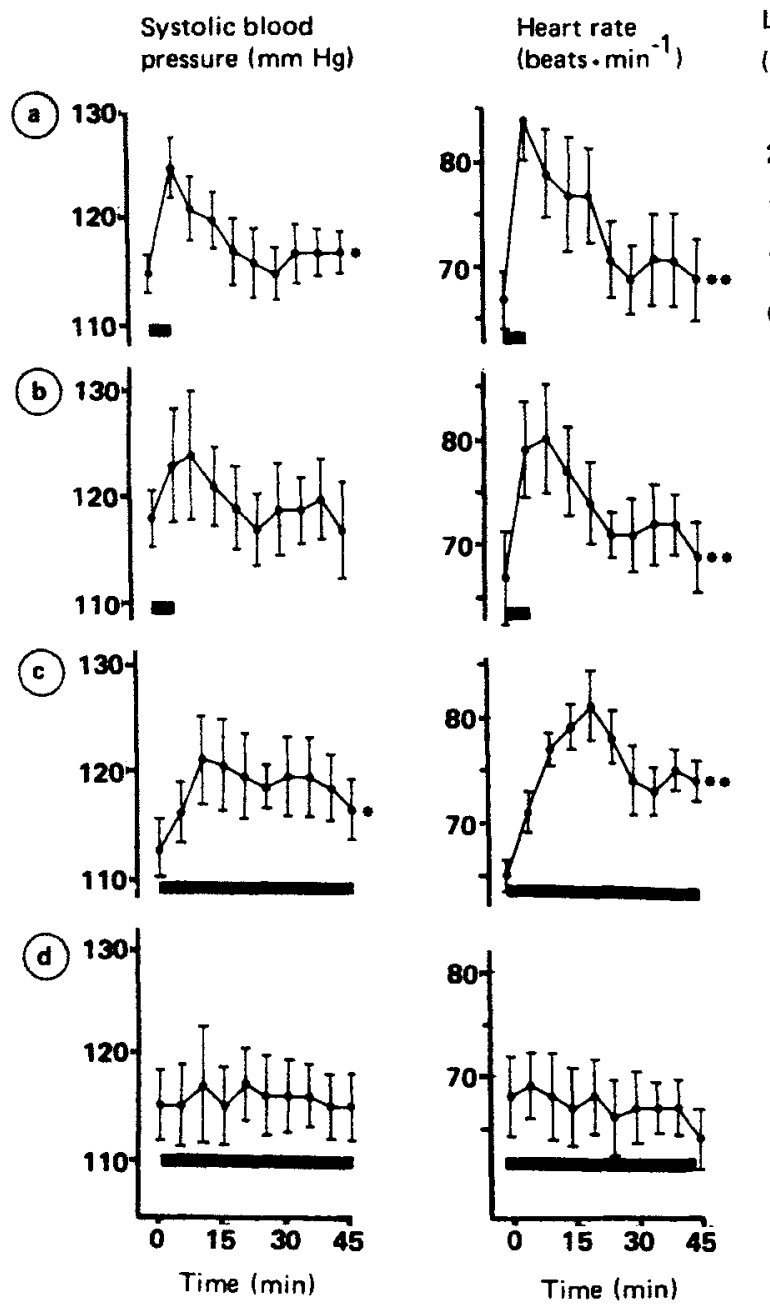
Log (blood flow)
$\left(\log \left[\mathrm{ml} \cdot \mathrm{min}^{-1}\right.\right.$ per $\left.\left.100 \mathrm{ml}\right]\right)$
resistance (AU)
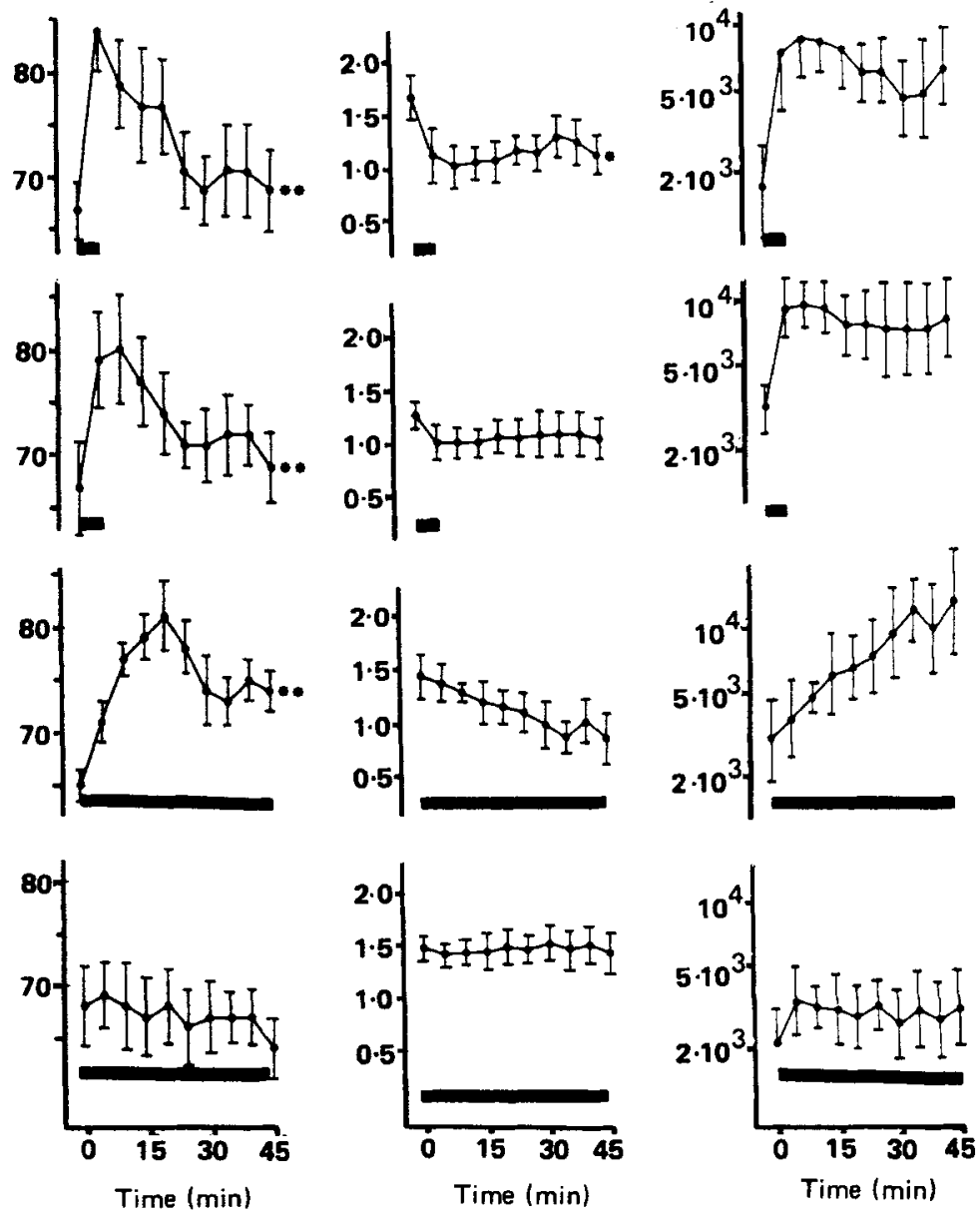

FIG 1 Haemodynamic response to cigarette smoking (with high (a) or low' (b) nicotine content) and to chewing nicotine gum (c) compared with placebo (d) (ordinary arabic gum). Horizontal bars represent time of exposure to nicotine. ${ }^{*} p<0.05$;

$* * p<0.001$ vs placebo.

$(p<0.001)$ after the cigarette with high nicotine content than after that with the low nicotine content. No significant correlation was found between either change in the haemodynamic values and the increase in plasma nicotine concentration.

\section{Discussion}

In the present study cigarette smoking and chewing nicotine gum induced notable and long lasting increases in systolic blood pressure and heart rate in healthy humans. A decrease in digital blood flow was also observed after smoking a cigarette with high nicotine content and during chewing nicotine gum. However, the latter change was not statistically significant. The absence of any haemodynamic effect during chewing the ordinary arabic gum eliminates the possibility of a non-specific reaction. Although the time course of these changes suggested a close relation with the increase in plasma nicotine concentration, no significant correlation was found between changes in any haemodynamic variable and the increases in plasma nicotine concentration, when the individual values were considered.

There are two main limitations in our study design. Firstly, with the timing that we used for the plasma nicotine measurements and the haemodynamic assessments, it is possible that the peak nicotine concentration during cigarette smoking or the maximal haemodynamic changes or both were not recorded. 

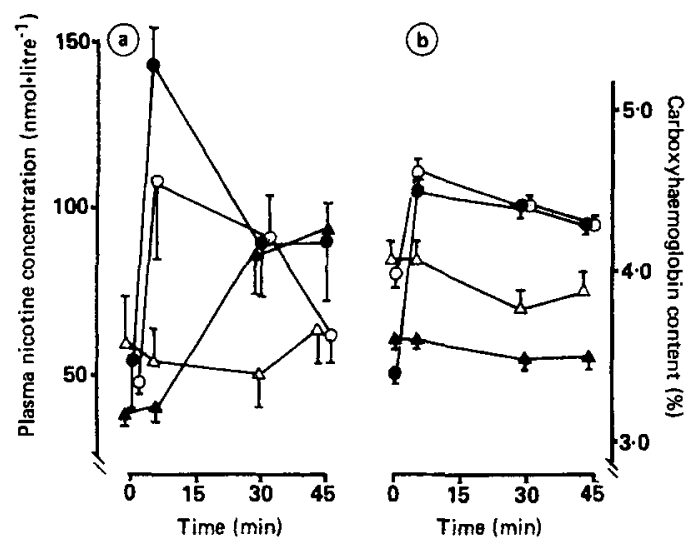

FIG 2 Nicotine (a) and carboxyhaemoglobin (b) concentrations after smoking or chewing $(\triangle)$ ordinary arabic gum (placebo), ( $\mathbf{\Delta})$ nicotine gum, (O) cigarette with high nicotine content, or $(\mathrm{O})$ cigarette with low nicotine content.

However, the reported absorption kinetics of nicotine after buccal administration or cigarette smoking ${ }^{13}$ suggest that the magnitude of such an error would be very small and could not account for the total absence of a correlation which we observed between the individual increases in plasma nicotine concentration and the haemodynamic changes. Secondly, the study was conducted on only six subjects. Although the double blind, crossover design is very powerful, ${ }^{8}$ statistical significance could not always be reached because of the large interindividual variations of the response to the different stimuli - especially digital blood flow and derived value of peripheral vascular resistance - and this was probably due to the small sample size.

However, our observations suggest that the nicotine induced haemodynamic effects occur as a result of mediators when the plasma concentration of nicotine has reached a threshold level. Such a threshold level might be characteristic for a given individual and might explain, at least partly, the large interindividual variability in susceptibility to smoking induced cardiovascular diseases.

It has been suggested that catecholamines, which are released locally from adrenergic nerve terminals, could be responsible for these haemodynamic reactions. ${ }^{3}$ Recently, Winniford and colleagues demonstrated in long term smokers with atherosclerotic coronary artery disease that the smoking induced vasoconstriction was due to a primary alpha adrenergically mediated increase in coronary artery tone. ${ }^{14}$ Apart from such an increase in alpha adrenergic tone, smoking may induce vasoconstriction in other ways. Stimulation of the secretion of arginine vasopressin, a powerful vasoconstrictor, has been observed, ${ }^{15}$ but the alterations in coronary blood flow caused by smoking do not seem to be related to the smoking induced changes in plasma arginine vasopressin. ${ }^{16} \mathrm{~A}$ role of arachidonic acid metabolites has also been proposed; smoking may induce the release of the potent vasoconstrictor thromboxane $\mathrm{A}_{2}$ from platelets ${ }^{4}$ and a diminution of the release of the vasodilator prostacyclin. ${ }^{6} 17$ However, these eicosanoids were not modified in coronary sinus blood during smoking induced vasoconstriction. ${ }^{2}$ In addition, their role in the mediation of the cold induced vasoconstriction has also been questioned. ${ }^{12}$ On the other hand, the plasma nicotine concentration increase with the high nicotine and low nicotine cigarettes was not statistically different at $p<0.05$, although the nicotine content of the cigarettes was quite different, 0.1 and $1.2 \mathrm{mg}$, as given by the manufacturer. If these contents are assumed to be correct, it may be that the filter abolishes the difference. However, the two cigarettes produced haemodynamic effects that did not differ statistically from each other. The digital blood flow, however, was less affected by the low nicotine cigarette than by the high nicotine cigarette.

Another finding of our study was that a gum containing $4 \mathrm{mg}$ of nicotine induced haemodynamic changes which were of the same order of magnitude as those caused by smoking a cigarette with a high nicotine content. The only difference was the delayed response, which can be explained by the delayed oral absorption. ${ }^{13}$ The maximal effects were observed at the end of the $45 \mathrm{~min}$ observation period while at the same time the effects caused by smoking had almost disappeared. Thus nicotine gum should be useful for only a short time for overcoming the withdrawal symptoms that occur when stopping smoking.

We thank Mrs A Ray, Mrs F Jassaud, and the nurses of the Medical Polyclinic for their excellent technical assistance.

\section{References}

1 Kannel WB, McGee D, Gordon T. A general cardiovascular risk profile: the Framingham Study. Am $J$ Cardiol 1976;38:46-51.

2 da Silva A, Widmer LK. Peripher-arterielle Verschlusskrankheit. In: Widmer LK, Stähelin HB, Nissen C, da Silva A, eds. Venen-Arterien-Krankheiten, koronare Herzkrankheit bei Berufstätigen (Basler-Studie I-III), Bem: Hans Huber Verlag, 1981: 137-237.

3 Cryer PE, Haymond MW, Santiago JV, Shah SD. Norepinephrine and epinephrine release and adrenergic mediation of smoking-associated hemodynamic and metabolic events. $N$ Engl J Med 1976;295:573-7.

4 Levine PH. An acute effect of cigarette smoking on platelet function. A possible link between smoking and arterial thrombosis. Circulation 1973;48:619-23.

5 Wennmalm A. Effects of nicotine on cardiac prostaglandin and platelet thromboxane synthesis. Br J Pharmacol 1978;64:559-63. 
6 Wennmalm A. Nicotine inhibits hypoxia and arachidonate-induced release of prostacyclin-like activity in rabbit hearts. Br J Pharmacol 1980;69:545-9.

7 Kannel WB. Update on the role of cigarette smoking in coronary antery disease. Am Heart J 1981;101:319-28.

8 Louis TA. Lavori PW, Bailar JCIII, Polansky M. Crossover and self-controlled designs in clinical research. $N$ Engl JMed 1984:310:23-31

9 Bennett T, Hosking DJ, Hamton JR. Cardiovascular responses to lower body negative pressure in normal subjects and in patients with diabetes mellitus. Cardiovasc Res 1979:13:31-8.

10 Huch R, Huch A, Lubbers DW. Transcutaneous measurements of blood $\mathrm{PO}_{2}\left(\mathrm{Tc}_{\mathrm{c}} \mathrm{P}_{2}\right)$. Method and application in perinatal medicine. J Perinat Med 1973:1:183-91.

11 Hengen $N$, Hengen M. Gaz-liquid chromatographic determination of nicotine in plasma. Clin Chem 1978:24:50-3.

12 Gresele P, Bounameaux $H$. Arnout J. Perez-Requejo JL. Deckmyn $H$. Vermylen J. Thromboxane $A_{2}$ and prostacyclin do not modulate the systemic hemodynamic response to cold in humans. J Lab Clin Med 1985;106:534-41.

13 Russel MAH, Jarvis MJ, West RJ, Feyerabend C. Buccal absorption of nicotine from smokeless tobacco sachets. Lancet 1985;ii: 1370

14 Winniford MD, Wheelan KR, Kremers MS, et al Smoking-induced coronary vasoconstriction in patients with atherosclerotic coronary artery disease: evidence for adrenergically mediated alterations in coronary artery tone. Circulation 1986:73:662-7.

15 Heyndrickx GR, Boettcher DH, Vatner SF. Effects of angiotensin. vasopressin, and methoxamine on cardiac function and blood flow distribution in conscious dogs. Am J Physiol 1976;231: : 1579-87.

16 Nicod P. Winniford MD, Campbell WB. Rehr RB. Firth BG Hillis LD. Alterations in coronary blood flow induced by cigarette smoking: lack of relation to plasma arginine vasopressin concentrations. Am J Cardiol 1984;54:667-8.

17 Sonnenfeld T. Wennmalm A. Inhibition by nicotine of the formation of prostacyclin-like activity in rabbit and human vascular tissue. Br J Pharmacol 1980;71:609-13.

\section{Correction}

In the paper by Furukawa ef al $(1987 ; 21: 717-724)$ the footnote to the table on $p 720$ should have read as follows: $\quad{ }^{*} p>0.05, \quad{ }^{* *} p<0.05, \quad{ }^{* * *} p<0.005$, $* * * * p<0.001$ vs values at $30 \mathrm{~s}$ during each stimulation. ${ }^{\dagger} p>0.05, \uparrow+t p<0.005,+++t p<0.001$ is values at $30 \mathrm{~s}$ during sympathetic stimulation. 